\title{
Comparative Analyses of Regeneration Potentiality of Eight Indigenous Aromatic Indica rice (Oryza sativa L.) Varieties
}

\author{
Saikat Paul ${ }^{1}$, Aryadeep Roychoudhury ${ }^{2 *}$ \\ ${ }^{1,2}$ Post Graduate Department of Biotechnology, St. Xavier's College (Autonomous), 30, Mother Teresa Sarani, \\ Kolkata - 700016, West Bengal, India \\ *Corresponding Author: aryadeep.rc@gmail.com, Tel.: +91-9903538297
}

Available online at: www.isroset.org

Received: 06/Feb/2019, Accepted: 23/Feb/2019, Online: 28/Feb/2019

\begin{abstract}
The development of an efficient in vitro regeneration system for economically-important aromatic rice cultivars is of urgent need for undergoing crop improvement through genetic modification. In the present work, comparative analysis of in vitro callus induction and regeneration efficiency of eight indigenous aromatic rice cultivars, viz., Kalonunia (KN), Gobindobhog (GB), Pusa Basmati (PB), Tulaipanji (TP), Radhunipagal (RP), IET 21261 (IET), Gandheswari (GN) and Radhatilak (RT) was carried out. The matured seeds were used as explants on Murashige and Skoog (MS) medium supplemented with $3 \mathrm{mg} \mathrm{L}^{-1}$ 2,4-dichlorophenoxyacetic acid and $30 \mathrm{~g} \mathrm{~L}^{-1}$ sucrose for callus induction, while embryogenic calli were transferred to MS medium supplemented with combination of hormones, $1 \mathrm{mg} \mathrm{L}^{-1}$ naphthalene acetic acid, $2 \mathrm{mg} \mathrm{L}^{-1} 6$ benzylaminopurine and $4 \mathrm{mg} \mathrm{L}^{-1}$ kinetin for plant regeneration. The present study showed that all the varieties exhibited a high frequency of callus induction, ranging from $63.19 \%$ to $98.33 \%$. The plant regeneration potential ranged from $93.43 \%$ to $33 \%$ depending on the genotypes examined. The maximum plant regeneration (\%) was noted in $\mathrm{KN}(93.43 \%)$ followed by GB (90.83\%), TP (89.34\%), RP (89\%), IET (75.92\%), GN (74.66\%) and RT (71\%), whereas the minimum regeneration potential was observed in PB (33\%). The regeneration potential was highly correlated with callus browning and callus production. The in vitro regenerated plants showed successful rooting and were well acclimatized under the conditions in growth chamber. Our observation highlighted a significant effect of genotype on callus induction ability, embryogenic response and plant regeneration capacity, suggesting the varietal difference in regeneration efficiency among the selected aromatic rice varieties.
\end{abstract}

Keywords-Aromatic rice, Oryza sativa, Indica rice, Regeneration, Callus induction, Plant growth regulators, Tissue culture, Matured seed explant

\section{INTRODUCTION}

Rice (Oryza sativa L.) is one of the most important staple food crops and the major source of calories for half of the world population; hence, genetic improvement of economically important rice cultivars, aimed at achieving higher rice productivity, has gained impetus in recent era of climate change and agricultural loss. India, among the ricegrowing countries, accounts for nearly one-fourth (22\%) of the rice produced in the world, with the first place occupied by China. Aroma and fragrance add value to the quality of rice, making it more demanding in Asia as well as Southeast Asia; further, it has recently gained popularity in the Middle East and Western markets $[1,2]$.

In India, aromatic rice is normally cultivated in Jammu and Kashmir, Himachal Pradesh, Punjab, Haryana, Uttarakhand and some parts of West Bengal and Kerala. The most popular aromatic rice in India is Basmati, which has a medium texture with a slender shape and long grain and less chalkiness [3]. Though a high-volume commodity, a class of aromatic, superfine premium rice has evolved its own market niches, making India one of the leading exporters of aromatic rice in the international market. In spite of high demand of aromatic rice in the international market, there are some constraints for the farmers to cultivate aromatic rice varieties, such as poor agronomic trait and reduced yield, dearth of disease resistant and salt-tolerant variety, lack of high yielding scented rice variety and proper cultural management. Because of its superior traits, Basmati rice gets a high price in international markets for its distinct aroma, long grain and soft and flaky texture. In addition, the country also produces hundreds of indigenous short-grained aromatic cultivars and landraces grown in distinct pockets of different states. West Bengal, being the 'rice bowl' of India is especially famous for its wide diversity of indigenous aromatic rice varieties such as Gobindobhog, Pusa Basmati, Tulaipanji, Radhunipagal, Gandheswari, Radhatilak, etc. These aromatic rice varieties also possess exemplary quality traits like aroma, fluffiness and taste. Gobindobhog in 
particular is a highly popular aromatic rice variety, cultivated in some districts of West Bengal, and is highly prized for its magnificent aroma and soft white texture; however, the variety is extremely salt-susceptible and even requires seed priming strategy to overcome the adverse effects of salt stress $[4,5]$. Hence, there is an urgent need for an efficient regeneration system for aromatic rice cultivars in order to undergo crop improvement through genetic modification or hybrid production.

Attempts to improve rice yield through conventional breeding program have met with very limited success. At present, in vitro technique of plant propagation from cell or tissue explants is an important and essential component of biotechnology, which is required for the genetic manipulation of crops. Efficient regeneration through in vitro micropropagation is very essential for the successful utilization of biotechnology in crop improvement of rice [6]. The identification and screening of useful cultivars for embryogenic callus formation and subsequent plant regeneration through in vitro system is a vital step in rice genetic improvement program [7, 8]. The use of matured seed embryos has a distinct advantage over other explants as starting material for in vitro rice regeneration [2, 9]. Recent advancement in biotechnology, such as transformation has enhanced the introgression of new genes from different sources to the cultivated species [10].

In spite of the low frequency of plant regeneration from callus, matured rice embryo is considered as one of the best explants for genetic transformation because of its availability throughout the year and easy handling as an explant compared to other tissues $[11,12]$. Lesser information is available on the in vitro regeneration procedure using matured embryos, particularly in indica rice than japonica type. In addition, a number of economically valuable indica varieties are recalcitrant to in vitro manipulation due to their poor callus production and regeneration ability [13]. Hence, it is essential to strategize an efficient protocol using matured embryos of indica rice for establishing a highly reproducible regeneration system that will enable rice transformation [6]. The dehusked form of the matured seed of the aromatic rice cultivar acts as a highly suitable explant for the formation of callus, amenable to multiple shoot formation and could be used for genetic transformation studies. However, an effective and robust tissue culture protocol system in aromatic rice varieties is relatively limited and less established. The selection of embryogenic callus is also critical before any regeneration study is initiated. Therefore, the purpose of the present investigation was to initiate high quality embryogenic calli from matured seeds, using the optimal concentration of 2, 4 dichlorophenoxyacetic acid (2,4-D), followed by establishing an easy regeneration

frequency $(\%)$ was calculated as below [15]. The calli were transferred to the fresh medium and the percentage of protocol for eight indigenous aromatic rice cultivars, viz., Kalonunia (KN), Gobindobhog (GB), Pusa Basmati (PB), Tulaipanji (TP), Radhunipagal (RP), IET 21261, Gandheswari (GN) and Radhatilak (RT). The differential potentiality of the aforementioned aromatic rice varieties for callus induction and regeneration using matured dehusked seeds was analyzed with the optimal concentration of plant growth regulators.

\section{MATERIALS AND METHODS}

\subsection{Plant materials}

The seeds of the eight aromatic rice varieties, viz., KN, GB, PB, TP, RP, IET, GN and RT were obtained from Chinsurah Rice Research Station, Hooghly, West Bengal, India. The matured seeds were used for the initiation of embryogenic calli and plant regeneration. The manually dehusked seeds of the aromatic rice cultivars were surface sterilized with $70 \%$ $(\mathrm{v} / \mathrm{v})$ ethanol for two minutes, followed by immersion in $0.1 \%(\mathrm{w} / \mathrm{v}) \mathrm{HgCl}_{2}$ for a time period of 15 minutes and shaken to mix well. The seeds were rinsed 8-10 times thoroughly using sterile distilled water, blotted dry on sterile Whatman paper $(3 \mathrm{~mm})$, prior to subjecting them for callus induction.

\subsection{In vitro germination}

The sterilized dehusked seeds of the eight varieties were separately inoculated for in vitro germination in Murashige and Skoog (MS) media [14] supplemented with 3\% (w/v) sucrose and solidified with agar $\left(8 \mathrm{~g} \mathrm{~L}^{-1}\right)$. The seeds were then incubated at $24 \pm 1^{\circ} \mathrm{C}$ in dark for four days. Each Petri plate consisted of 10-12 seeds and ten plates were maintained for each variety. The experiment was replicated thrice. Seed germination was observed after four days in the form of radicle emergence, and the germination percentage was expressed as: Embryo germination percentage $(\%)=$ (Number of embryo germinated / Total number of seeds inoculated) $\times 100$.

\subsection{Callus induction medium}

For callus induction, the germinated embryos were cut and inoculated on Petri plate on callus induction medium (CIM) and incubated at $24 \pm 1^{\circ} \mathrm{C}$ in dark for 14 days. The scutellum-derived embryogenic calli were next transferred to fresh CIM for two week under the same condition; the nonembryogenic calli (compact, non-friable calli that develop root like structures) were discarded. CIM was prepared using basal MS medium containing all vitamins [14] supplemented with $30 \mathrm{~g} \mathrm{~L}^{-1}$ sucrose, $3 \mathrm{mg} \mathrm{L}^{-1}$ 2,4-D, gelled with $8 \mathrm{~g} \mathrm{~L}^{-1}$ agar, and $\mathrm{pH}$ adjusted to 5.8. The data were recorded after four week of culture initiation. The callus induction browning in the embryogenic callus was calculated. Callus induction frequency $(\%)=[($ Total number of cultured seed 
with callus - Total number of initiated callus) / Total number of cultured seed] $\times 100$.

\subsection{Plant regeneration}

After four week of maintenance, the embryonic calli were transferred to MS regeneration medium (RM) supplemented with $1 \mathrm{mg} \mathrm{L}^{-1}$ naphthalene acetic acid (NAA), $2 \mathrm{mg} \mathrm{L}^{-1} 6$ benzylaminopurine (BAP), $4 \mathrm{mg} \mathrm{L}^{-1}$ kinetin, $30 \mathrm{~g} \mathrm{~L}^{-1}$ sucrose, $8 \mathrm{~g} \mathrm{~L}^{-1}$ agar, and $\mathrm{pH}$ adjusted to 5.8. The culture was maintained in growth chamber at $24^{\circ} \mathrm{C}$ under $16 \mathrm{~h}$ day $/ 8 \mathrm{~h}$ night photoperiodic cycle, with a light intensity of 2000 lux using fluorescent tubes. The frequency of plant regeneration was calculated as below [15]. Regeneration frequency $(\%)=$ [Number of regenerated calli / Number of calli maintained] $\times$ 100 .

\subsection{Statistical analysis}

All statistical analyses were performed using the $\mathrm{R}$ statistical program. The analyses were performed by one-way analysis of variance (ANOVA) for each cultivar and the $\mathrm{P}$ value was obtained. Three independent biological replicates for each trait of all the genotypes were used for this analysis. The Tukey's honestly significant difference (HSD) test was conducted to identify the mean values that were significantly different from each other at $\mathrm{P}<0.05$ level.

\section{RESUlTS AND DISCUSSION}

Tissue culture technique has been proposed as a novel strategy in plant breeding program that allows the development of genetic variability. This technique involves standardizing a culture condition in which de-differentiated cells or tissues could be established to allow their proliferation and subsequent regeneration. However, an effective and robust tissue culture protocol system in indigenous aromatic rice varieties is relatively limited and less established. In the present study, in vitro techniques for callus induction and plant regeneration have been compared using matured seeds as explants from eight indigenous aromatic rice varieties of West Bengal, India, to facilitate the regeneration protocol which can be used to recover germplasm.

\subsection{Percentage of embryo germination}

Rice improvement through in vitro approaches or hybridization requires an efficient regeneration protocol especially for indica rice varieties which, among cereals, are less amenable to culture. Seed dormancy, embryo abortion and failure of complete plant production are the results of interspecific barriers of hybridization program [16]. In addition, matured seeds of some traditional rice varieties may not always germinate in culture media due to their recalcitrant nature or due to seed dormancy. Hence, it is important to develop an efficient protocol for breaking seed dormancy and plant regeneration from matured seed cultures in rice. Here, we carried out embryo germination test using dehusked matured seeds of eight aromatic rice genotypes, viz., KN, GB, PB, TP, RP, IET, GN and RT on germination medium (Figure 1a, b). In MS medium supplemented with $3 \%(\mathrm{w} / \mathrm{v})$ sucrose, the seed germination was initiated within five to nine days. The fastest germination time was recorded for KN, RP, GN and RT followed by GB and TP; while the maximum time necessary for germination was noted for $\mathrm{PB}$ and IET (Figure 1a). In addition, the embryo germination percentage was also recorded. The highest embryo germination percentage was noted for GB (96.7\%) and RP (96.3\%) followed by TP (93\%), GN (85.3\%), RT (83.6\%), KN $(60.4 \%)$, IET $(44.7 \%)$ and the lowest in PB $(34.3 \%)$ (Figure 1b). A significant $(\mathrm{p}<0.001)$ negative correlation was observed between embryo germination time and germination percentage (Figure 5a). The results of embryo germination percentage and germination time indicated that among the eight aromatic rice cultivars, PB and IET showed low response to MS culture media (3\% sucrose) possibly because of prevailing dormancy in the seed. Previous studies have also used MS medium with agar as a solidifying agent [17-20] and sugar [6] for germination of rice seeds under in vitro conditions.

\subsection{Callus induction and percentage of browning}

Murashige and Skoog medium is considered as the most suitable culture medium for callus induction of rice cultivars $[21,22]$. Previous reports have also shown high callus induction on MS medium supplemented with 2,4-D [23]. In the present work, a comparative study was carried out with several indigenous aromatic rice cultivars showing the best callus induction potential (Figure 2). The germinated embryos of eight aromatic rice cultivars were inoculated on MS media supplemented with $3 \mathrm{mg} \mathrm{L}^{-1} 2,4-\mathrm{D}$ for callus induction. Our results showed that callus induction occurred between 8-14 days after inoculation with the cultivars GB, $\mathrm{TP}$ and RP, requiring minimum time for callus induction, followed by KN, GN and RT. The maximum time for callus induction was noted for IET followed by PB which was significantly different from that for GB, TP and RP (Figure 3a). The varietal difference with regard to callus induction time was further supported by our ANOVA study which showed significant $(\mathrm{p}<0.001)$ effect of rice genotypes on callus induction time. A significant ( $\mathrm{p}<0.001)$ negative correlation between callus induction time and percentage of callus induction was also noteworthy (Figure 5b). Almost all the inoculated seeds developed scutellar calli within 14 days of inoculation on CIM; however, non-embryogenic calli were discarded and only embryogenic calli were subcultured further on CIM. The callus induction frequencies ranged from $63.19 \%$ to $98.33 \%$ depending on the genotypes examined. The maximum $(98.33 \%)$ callus induction 
frequency was observed in RP which was not significantly different from GB (97.67\%), TP (93.29\%) and GN (89.97\%), but significantly different from KN (74.84\%), PB (64.75\%) and IET $(63.19 \%)$ (Figure $3 b)$. This result clearly indicated the varietal effect on the callus induction, which was further supported by ANOVA, revealing a significant $(\mathrm{p}<0.001)$ effect of genotype on callus induction frequency (Table 1).
Previous reports also showed the effect of rice genotypes on the variability of callus induction potential $[24,25]$. The role of 2,4-D in promoting somatic embryogenesis, dedifferentiation and cell division in rice has been reported earlier [26]. The phytohormone also modulates the endogenous indole acetic acid (IAA) level in explant tissues [27]. These genotypic variations are probably
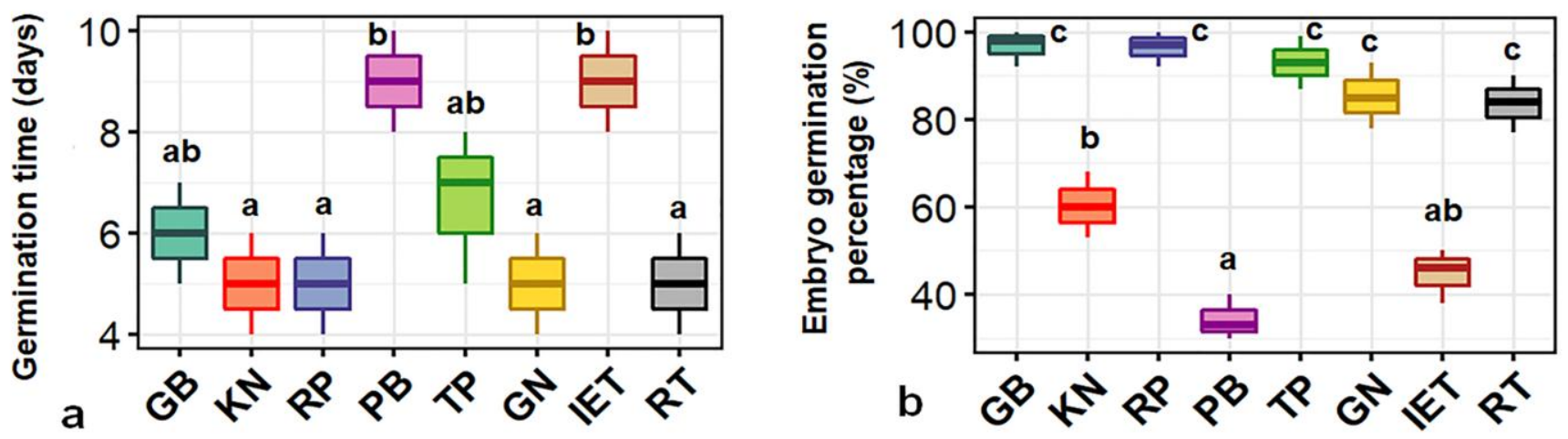

Figure 1. Embryo germination time (a) and germination percentage (b) from matured seeds of eight aromatic rice cultivars, viz., Gobindobhog (GB), Kalonunia (KN), Radhunipagal (RP), Pusa Basmati (PB), Tulaipanji (TP), Gandheswari (GN), IET 21261 (IET) and Radhatilak (RT). For all box plots, central bold line indicates the median; boxes delineate 1st and 3rd quartiles, while the lower and upper lines refer to minimum and maximum values respectively. Three biological replicates $(\mathrm{n}=$ $3)$ were used for analysis. Similar letters indicate no significant difference $(P<0.05)$ using Tukey's HSD test.

due to the differential accumulation of phytohormones, depending upon the spatial and temporal distribution, and their physiological and developmental stages [28]. The critical concentration of 2,4-D for callus induction and embryogenic callus formation from matured seeds of cereal crops is between $10^{-5}$ to $10^{-7} \mathrm{M}$ [29]. The possible reason for requiring different concentrations of 2,4-D for callus proliferation may be due to the variation of genetic makeup in the endogenous levels of phytohormones which influence the callus induction and proliferation [27]. One of the inevitable components of tissue culture and transformation processes is subculturing, and callus growth and browning becomes more evident with the increased passages of subculture. The main obstacle for transgenic manipulation of rice by callus culture from matured seed is callus browning which prevents normal regeneration process due to the death of brown calli in indica rice variety. We measured the percentage of callus browning for the eight aromatic rice cultivars. Overall, the highest browning occurred in PB (71.55\%) followed by TP (44.25\%) which was significantly different from GB (11.30\%) and RT (12.25\%) (Figure 3c). The GB and RT showed minimum callus browning in MS medium supplemented with $3 \mathrm{mg} \mathrm{L}^{-1}$ 2,4-D. This result clearly indicated the genetic variability of rice cultivars with regard to callus browning which corresponds with the earlier reports $[30,31]$. The data from ANOVA supported our observation, showing significant $(\mathrm{p}<0.001)$ effect of genotype on callus browning. We also noted a significant ( $\mathrm{p}$ $<0.01$ ) negative correlation between callus induction and percentage of browning (Figure 5c), pointing to the fact that the decrease of callus induction was related to the increased rate of callus browning. An earlier study also reported that a decrease in the rate of callus growth is occasionally related to the appearance of a brown coloured area [32]. The callus browning or regeneration of albino plants depend on the low concentration of 2,4-D [33] and high temperature [8]. However, in our study, $3 \mathrm{mg} \mathrm{L}^{-1} 2,4-\mathrm{D}$ and $24^{\circ} \mathrm{C}$ were used for callus induction, which are supposed to be the optimum conditions for callus induction [34]. The relationship of peroxidase (POD) and polyphenol oxidase (PPO) activities with callus browning has been shown earlier [35]. During cell damage, the cytoplasmic and vacuolar contents are mixed and phenolic compounds can readily become oxidized by air, PODs or PPOs. The catalytic activity of the enzyme may be inhibited by oxidized phenolic compounds which cause darkening of the culture medium and subsequent lethal browning of explants [36]. The unsuitable culture conditions are reported to lead to callus browning, viz., inappropriate $\mathrm{NH}_{4}{ }^{+}$concentrations [37], light level [38], temperature [8], thiamine [39], and auxin [40]. The genetic linkage analysis indicated that one single locus was responsible for rice callus browning and that mapped to chromosome 1 [41]. 

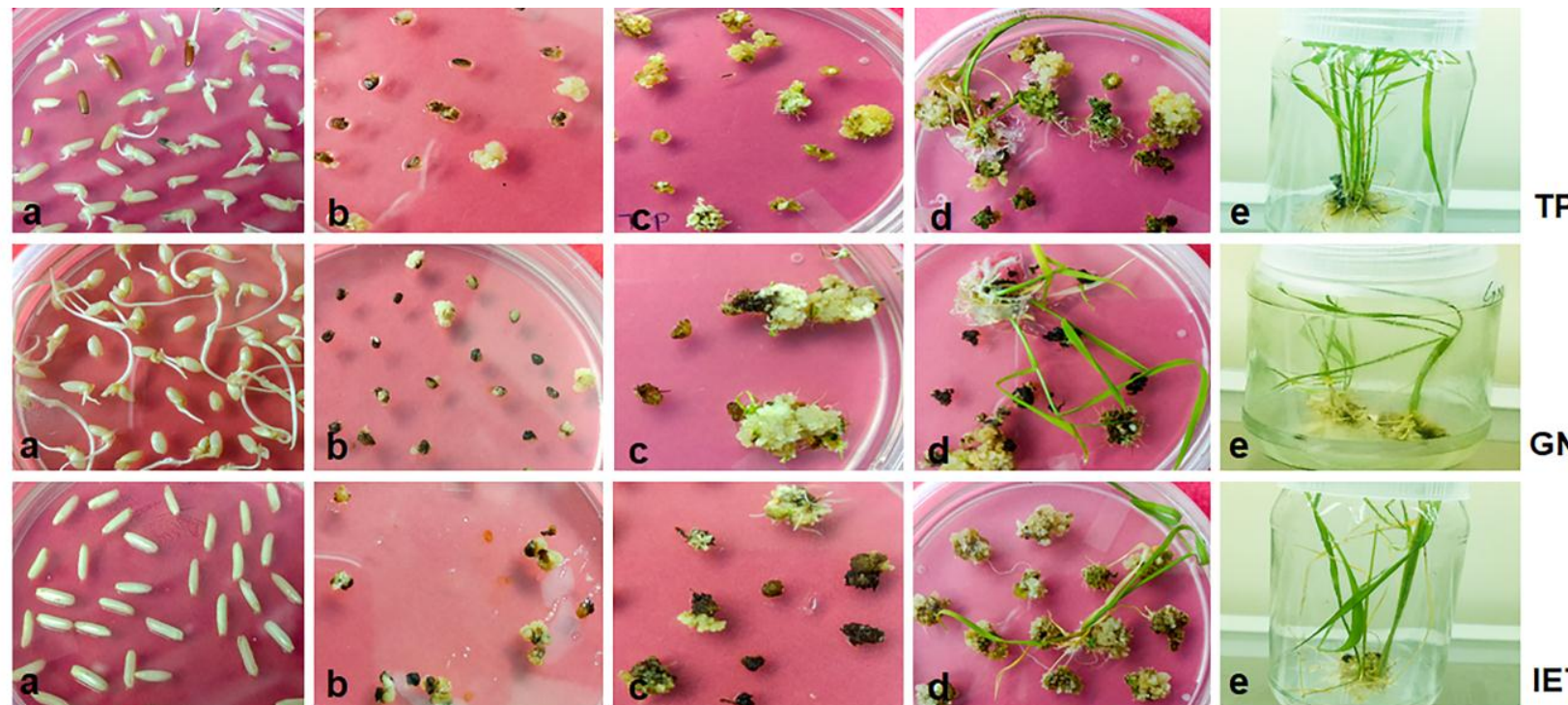

TP
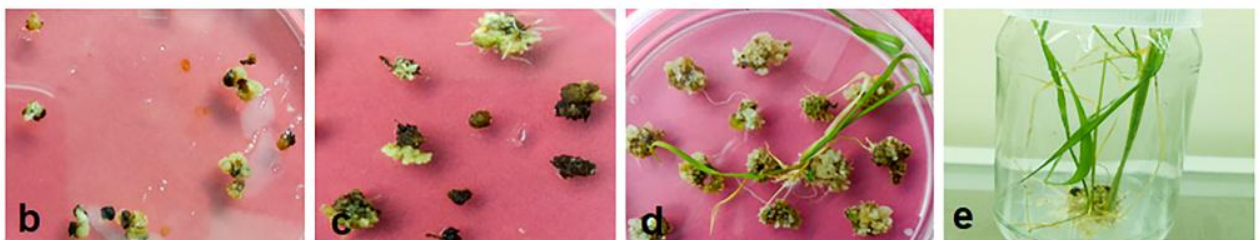

GN
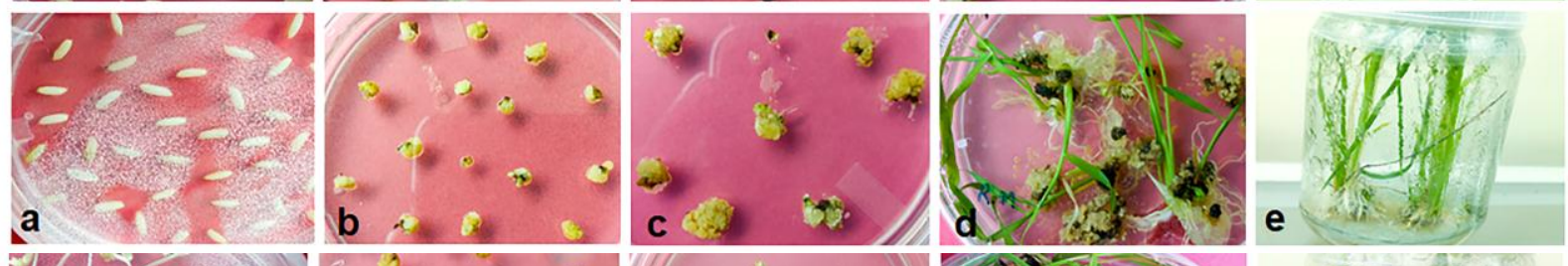

IET
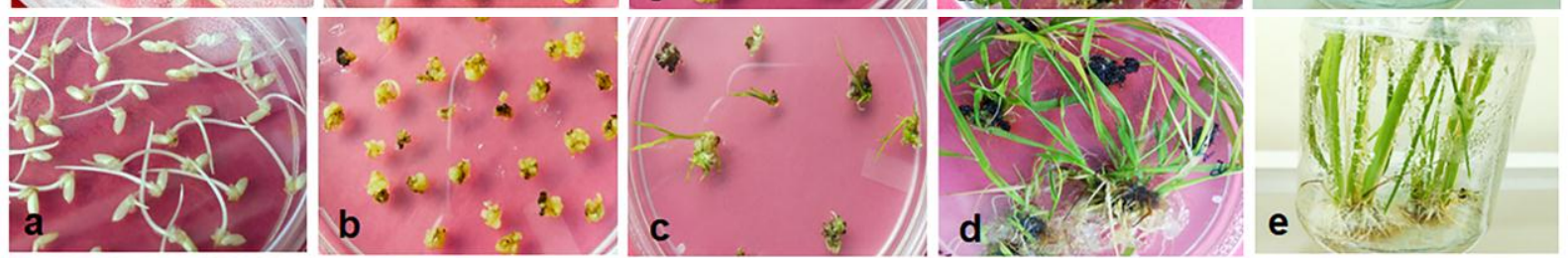

RT
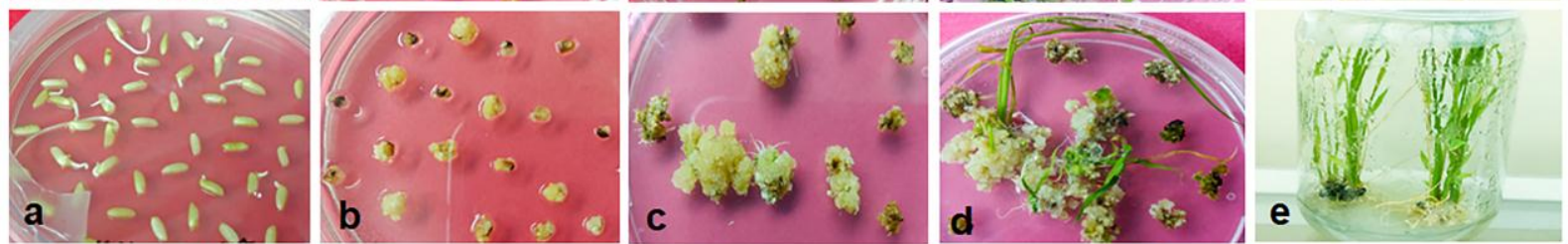

GB
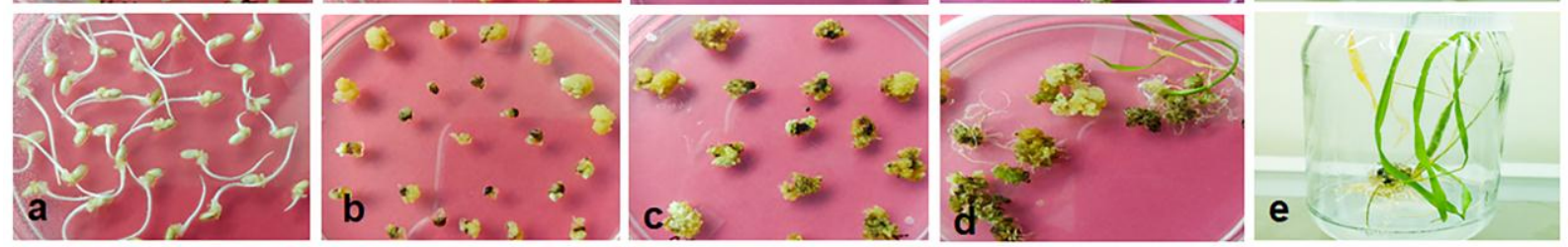

KN
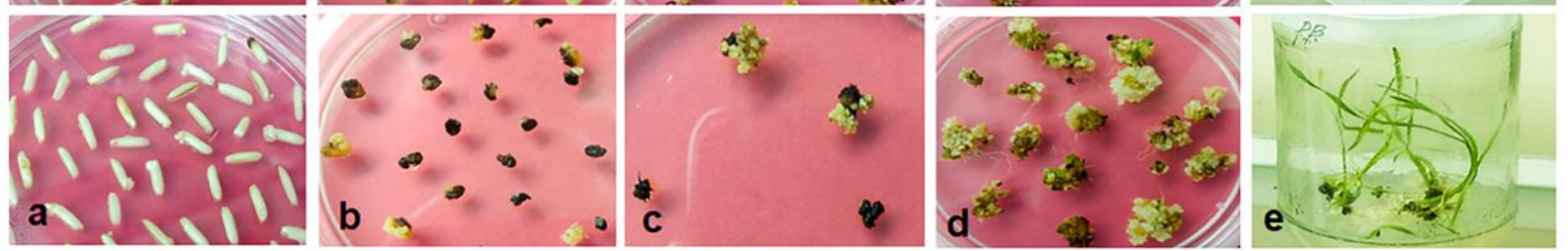

RP

Figure 2. Callus induction and regeneration of matured embryos of eight aromatic rice cultivars, viz., Gobindobhog (GB), Kalonunia (KN), Radhunipagal (RP), Pusa Basmati (PB), Tulaipanji (TP), Gandheswari (GN), IET 21261 (IET) and Radhatilak (RT); (a) embryo germination, (b) callus induction, (c) shoot bud initiation, (d) shoot induction and elongation of multiple shoots, (e) regenerated plant. 

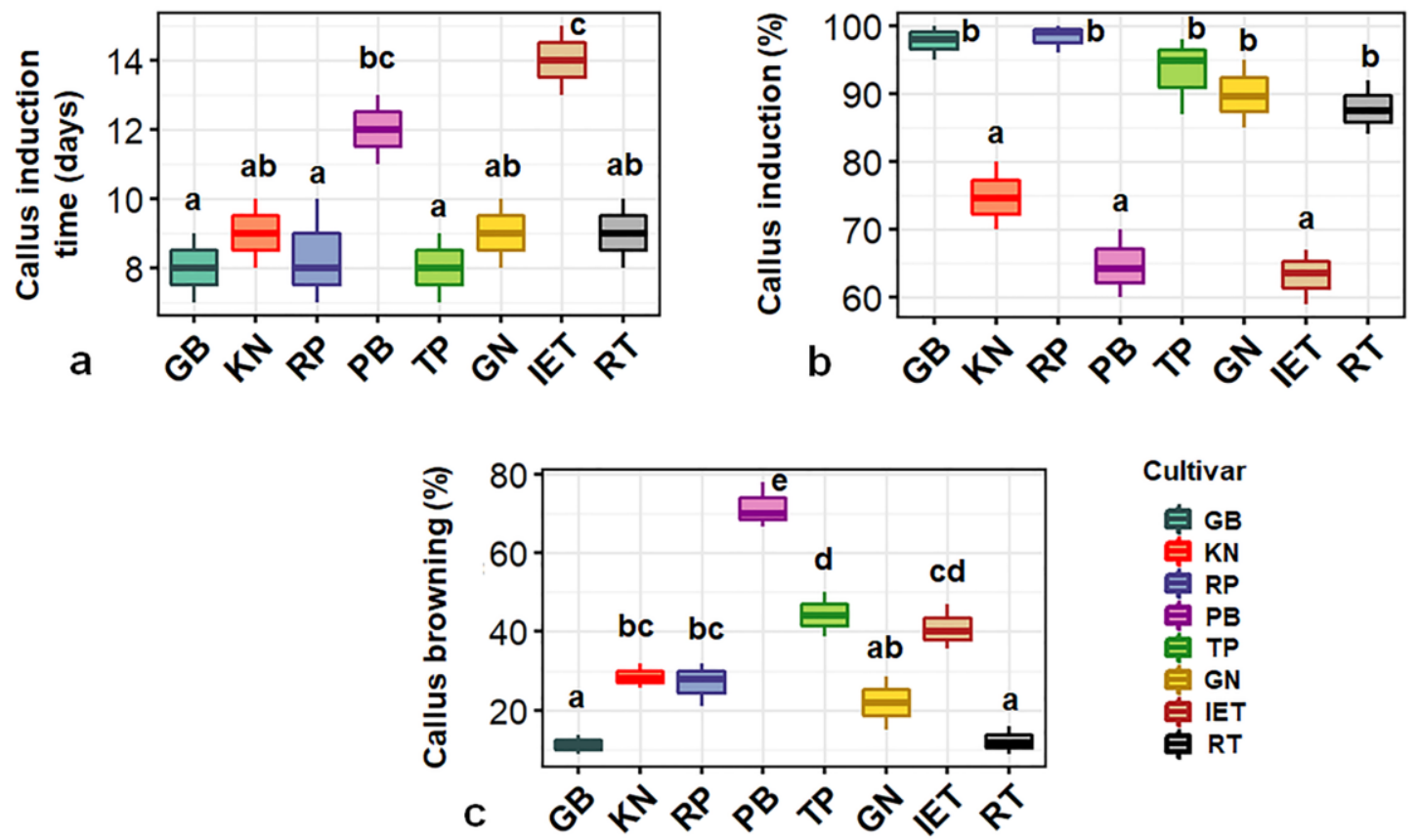

Figure 3. Callus induction time (a), percentage of callus induction (b) and percentage of callus browning (c) of eight aromatic rice cultivars, viz., Gobindobhog (GB), Kalonunia (KN), Radhunipagal (RP), Pusa Basmati (PB), Tulaipanji (TP), Gandheswari (GN), IET 21261 (IET) and Radhatilak (RT). For all box plots, central bold line indicates the median; boxes delineate 1st and 3rd quartiles, while the lower and upper lines refer to minimum and maximum values respectively. Three biological replicates $(n=3)$ were used for analysis. Similar letters indicate no significant difference $(P<0.05)$ using Tukey's HSD test.

Table 1. ANOVA table for different trait, related to callus induction and regeneration of eight aromatic rice cultivars, viz., Gobindobhog (GB), Kalonunia (KN), Radhunipagal (RP), Pusa Basmati (PB), Tulaipanji (TP), Gandheswari (GN), IET 21261 (IET) and Radhatilak (RT). P-values of one-way ANOVA analyzing the effects of genotypes (G) are shown. The asterisks represent significant effects of $\mathrm{G}$ on the callus induction and regeneration frequency.

\begin{tabular}{ll}
\hline \multicolumn{1}{c}{ Trait } & Genotype $(\mathbf{G})$ \\
\hline Embryo germination time & $0.0003236 * * *$ \\
Embryo germination percentage & $1.053 \mathrm{e}-09 * * *$ \\
Callus induction time & $2.491 \mathrm{e}-05 * * *$ \\
Callus induction percentage & $2.795 \mathrm{e}-08 * * *$ \\
Callus browning & $1.723 \mathrm{e}-09 * * *$ \\
Regeneration frequency & $2.677 \mathrm{e}-08 * * *$ \\
\hline
\end{tabular}

Significance level: $* \mathrm{P}<0.05, * * \mathrm{P}<0.01, * * * \mathrm{P}<0.001$

\subsection{Plant regeneration}


The main objective of the present study was to compare the regeneration potential of eight indigenous aromatic rice cultivars, since the regeneration step is important and necessary to derive plantlets for crop improvement program [42]. Many high yielding, elite rice cultivars show low regeneration potential; however, regeneration capacity of plant varies, depending on their genetic background [43] and is considered as a major bottleneck for crop improvement via introgression of desirable genes in rice genome through transgenic approach $[44,45]$.
In the current study, high quality embryogenic calli were transferred to the regeneration medium (RM) in order to investigate their potential for plant regeneration. The plant regeneration potential ranged from $93.43 \%$ to $33 \%$ depending on the genotypes examined. The maximum plant regeneration capability was noted in $\mathrm{KN}(93.43 \%)$ followed by GB (90.83\%), TP $(89.34 \%)$, RP (89\%), IET $(75.92 \%)$, GN $(74.66 \%)$ and $\mathrm{RT}(71 \%)$. The minimum regeneration potential was observed in PB $(33 \%)$ which was significantly different from other aromatic rice cultivars (Figure 4).

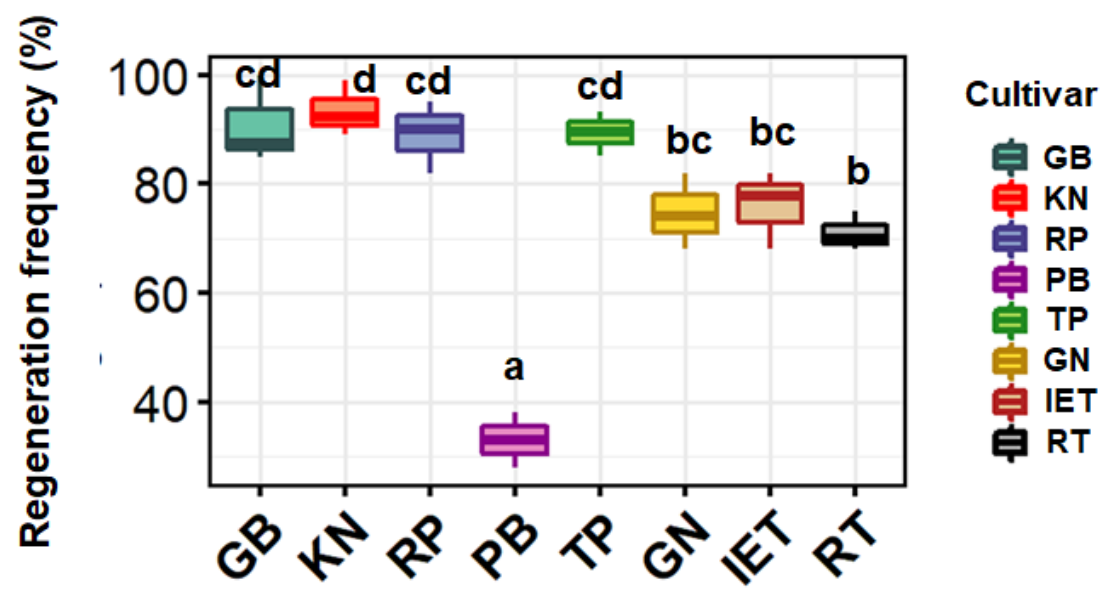

Figure 4. Regeneration frequency of eight aromatic rice cultivars, viz., Gobindobhog (GB), Kalonunia (KN), Radhunipagal (RP), Pusa Basmati (PB), Tulaipanji (TP), Gandheswari (GN), IET 21261 (IET) and Radhatilak (RT). For all box plots, central bold line indicates the median; boxes delineate 1st and 3rd quartiles, while the lower and upper lines refer to minimum and maximum values respectively. Three biological replicates $(n=3)$ were used for analysis. Similar letters indicate no significant difference $(\mathrm{P}<0.05)$ using Tukey's HSD test.

A significant $(\mathrm{p}<0.001)$ negative correlation was observed between callus browning and plant regeneration capacity (Figure $5 \mathrm{~d}$ ), while positive correlation $(\mathrm{p}<0.01)$ between percentage of callus induction and plant regeneration capacity (Figure 5e), indicating callus induction capacity as an ideal index for the ability of the callus to generate plantlets during micropropagation. The aromatic rice cultivars which showed high callus induction percentage during the first week of culture were more probable to regenerate plantlets after several weeks of culture. An earlier study also reported high positive correlation between the embryogenic calli production and capacity for plant regeneration [46]. Upon transfer of the calli to RM and maintaining there for two weeks, greening effect was observed for all the varieties. After three weeks, the green spots developed multiple shoots, followed by in vitro plantlet formation, and then developing into healthy plants (Figure 2). Naphthalene acetic acid was used in the RM according to Iqbal et al. [24]. Earlier study reported that weak plantlets were developed in the absence of NAA [47] and also that higher amounts of BAP and kinetin may stimulate initial cell division, playing an important role in somatic embryogenesis and plantlet regeneration $[34,48]$. In our study, a combination of $1 \mathrm{mg} \mathrm{L}^{-1} \mathrm{NAA}, 2 \mathrm{mg} \mathrm{L}^{-1} \mathrm{BAP}$ and $4 \mathrm{mg} \mathrm{L}^{-1}$ kinetin contributed to the highest plantlet regeneration in all the indigenous aromatic rice cultivars. The role of kinetin in improving somatic embryogenesis by influencing mitosis, cytokinesis, total protein synthesis, lignin biosynthesis and vascular differentiation is well known from earlier reports [49]. 

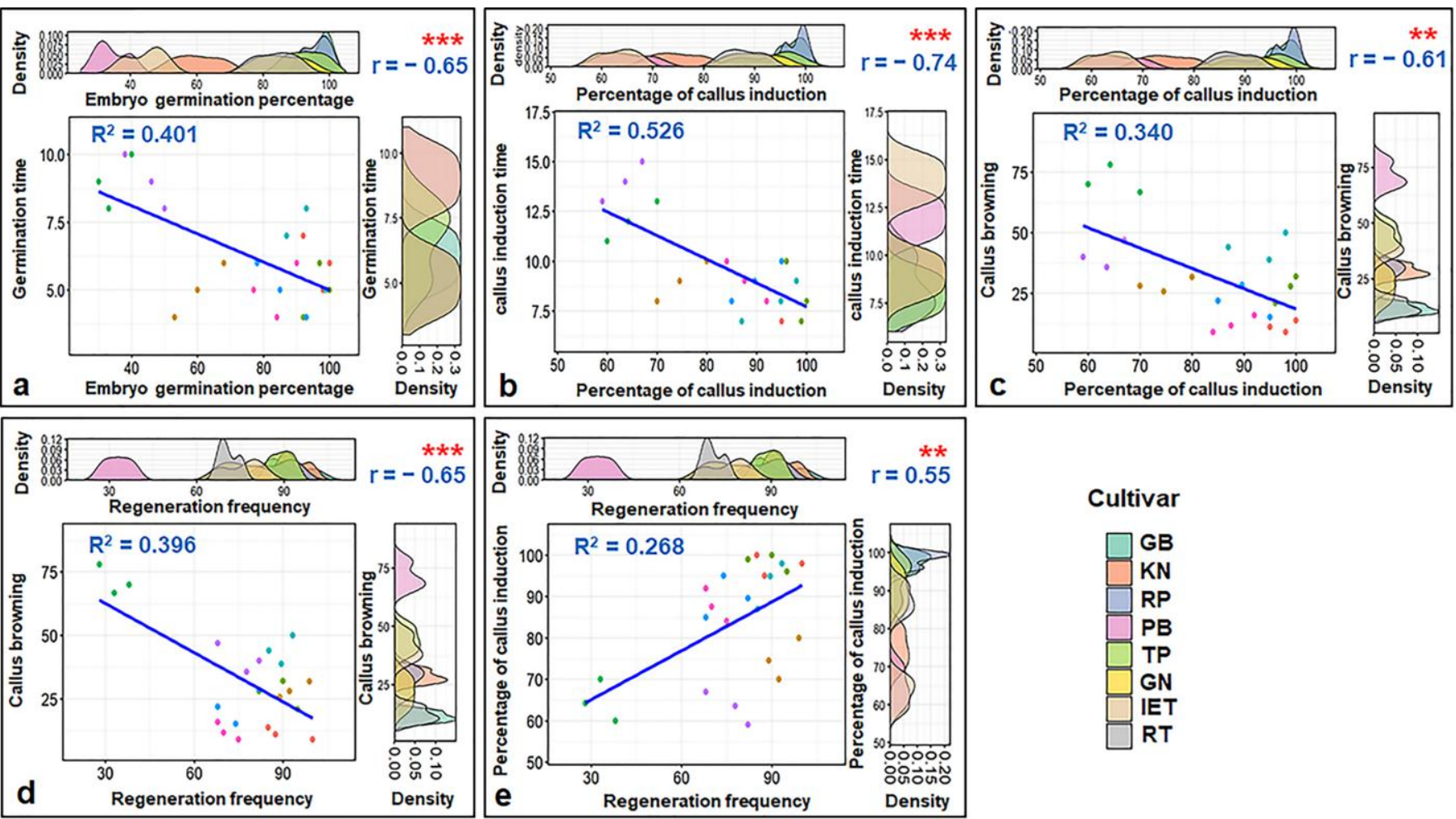

Figure 5. Correlation between embryo germination time and embryo germination percentage (a), between callus induction time and percentage of callus induction (b), between callus browning and percentage of callus induction (c), between callus browning and regeneration frequency (d), and between percentage of callus induction and regeneration frequency (e). The corresponding distribution curves of aromatic rice cultivars, viz., Gobindobhog (GB), Kalonunia (KN), Radhunipagal (RP), Pusa Basmati (PB), Tulaipanji (TP), Gandheswari (GN), IET 21261 (IET) and Radhatilak (RT) are also shown for each trait. The Pearson's correlation coefficient $(\mathrm{r})$, regression values $\left(\mathrm{R}^{2}\right)$ and their significance level $(* * * \mathrm{p}<0.001$, **p $<0.01)$ are displayed on top right of each segment.

\section{CONCLUSION}

In the present work, a comparative analysis of in vitro callus induction and regeneration efficiency of indigenous aromatic rice cultivars was carried out. We report here a successful high-frequency regeneration protocol from matured rice embryos of eight aromatic rice cultivars from West Bengal, India. Our result showed a high seed germination rate in MS medium supplemented with $3 \%(\mathrm{w} / \mathrm{v})$ sucrose for all the varieties except $\mathrm{PB}$ and IET. High callus induction frequency was observed for all the rice varieties in MS medium supplemented with $3 \mathrm{mg} \mathrm{L}^{-1} 2,4-\mathrm{D}$ and $30 \mathrm{~g} \mathrm{~L}^{-1}$ sucrose. A significant negative correlation was noted for callus induction time and callus browning with callus induction frequency. Further, our result showed the potential of plant growth hormone combination of $1 \mathrm{mg} \mathrm{L}^{-1} \mathrm{NAA}, 2$ $\mathrm{mg} \mathrm{L}^{-1} \mathrm{BAP}$ and $4 \mathrm{mg} \mathrm{L}^{-1}$ kinetin to promote regeneration of the chosen aromatic rice varieties. The maximum regeneration potential was noted in $\mathrm{KN}$ followed by GB, TP, $\mathrm{RP}, \mathrm{IET}, \mathrm{GN}$ and RT, and minimum regeneration potential in PB. Further, we observed a significant negative correlation between callus browning and plant regeneration capacity, while positive correlation between percentage of callus induction and plant regeneration capacity, indicating callus induction capacity as a good index for assessing the ability of callus to regenerate plantlets. All the eight cultivars responded, though with different extent, to in vitro culture especially with respect to embryogenic callus production and plant regeneration. Overall, our findings showed a significant effect of genotype on the callus induction ability, embryogenic response and plant regeneration capacity in the selected aromatic rice cultivars. The work will pave the way for future crop improvement program of economically important aromatic rice varieties through transformation of desirable genes into their genome for obtaining desirable traits.

\section{ACKNOWLEDGEMENTS}

Financial assistance from Science and Engineering Research Board (SERB), Government of India through the research 
grant (SR/FT/LS-65/2010) and from Council of Scientific and Industrial Research (CSIR), Government of India, through the research grant [38(1387)/14/EMR-II] to Dr. Aryadeep Roychoudhury is gratefully acknowledged. The

\section{REFERENCES}

[1] K. Sakthivel et al., "Development of a simple functional marker for fragrance in rice and its validation in Indian Basmati and non-Basmati fragrant rice varieties," Mol Breed., vol. 24, Issue. 2, pp. 185-190, 2009.

[2] Z. A. Rahman et al., "Efficient plant regeneration of Malaysian aromatic rice (Oryza sativa L.) through somatic embryogenesis," Emirates J. Food Agric., vol. 27, Issue. 11, pp. 857-863, 2015.

[3] S. Kamath et al., "Basmati rice: its characteristics and identification," J. Sci. ofFood Agric., vol. 88, pp. 1821-1831, 2008.

[4] S. Paul, A. Roychoudhury, "Effect of seed priming with spermine/spermidine on transcriptional regulation of stress-responsive genes in salt-stressed seedlings of an aromatic rice cultivar," Plant Gene, vol. 11, pp. 133-142, 2017.

[5] S. Paul, A. Roychoudhury, "Seed priming with spermine and spermidine regulates the expression of diverse groups of abiotic stressresponsive genes during salinity stress in the seedlings of indica rice varieties," Plant Gene, vol. 11, Issue. B, pp. 124-132, 2017.

[6] M. N. Hoque, L. Rahman, L. Hassan, "Effect of culture media on seed dormancy and callus induction ability of some wild and cultivated rice genotypes," Biotechnology, vol. 6, Issue. 1, pp. 61-63, 2007.

[7] P. Puhan, E. A. Siddiq, "Protocol optimization and evaluation of rice varieties response to in vitro regeneration," Adv. Biosci. Biotechnol., vol. 4, pp. 647-653, 2013.

[8] M. E. Hoque, J. W. Mansfield, "Effect of genotype and explant age on callus induction and subsequent plant regeneration from root-derived callus of Indica rice genotypes," Plant Cell. Tissue Organ Cult., vol. 78, Issue. 3, pp. 217-223, 2004.

[9] E. Shahsavari, A. A. Maheran, A. S. N. Akmar, M. M. Hanafi, "The effect of plant growth regulators on optimization of tissue culture system in Malaysian upland rice," African J. Biotechnol., vol. 9, Issue. 14, pp. 2089-2094, 2010.

[10] K. K. Sahoo, A. K. Tripathi, A. Pareek, S. K. Sopory, S. L. SinglaPareek, "An improved protocol for efficient transformation and regeneration of diverse indica rice cultivars," Plant Methods, vol. 7, Issue. 1, pp. 49, 2011

[11] J. Chen, R. Yue, H. Xu, X. Chen, "Study on plant regeneration of wheat mature embryos under endosperm-supported culture," Agric. Sci. China, vol. 5, Issue. 8, pp. 572-578, 2006.

[12] K.W. Lee et al., "High frequency plant regeneration from mature seedderived callus of Italian ryegrass (Lolium multiflorum) cultivars," African J. Biotechnol., vol. 8, Issue. 24, pp. 6828-6833, 2009.

[13] M. Ramesh, V. Murugiah, A. K. Gupta, "Efficient in vitro plant regeneration via leaf base segments of indica rice (Oryza sativa L.)," Indian J. Exp. Biol., vol. 47, Issue. 1, pp. 68-74, 2009.

[14] T. Murashige, F. Skoog, "A revised medium for rapid growth and bio assays with tobacco tissue cultures," Physiol. Plant., vol. 15, Issue. 3, pp. 473-497, 1962.

[15] M. A. Zaidi et al., "Optimizing tissue culture media for efficient transformation of different indica rice genotypes," Agron. Res., vol. 4, Issue. 2, pp. 563-575, 2006.

[16] A. L. Mariam, A. H. Zakri, M. C. Mahani, M. N. Normah, "Interspecific hybridization of cultivated rice, Oryza sativa L. with the wild rice, O. minuta Presl.," Theor. Appl. Genet., vol. 93, Issue. 5-6, pp. 664-671, 1996. authors are thankful to University Grants Commission (UGC), Government of India, for providing Senior Research Fellowship to Saikat Paul.

[17] H. Afrasiab, R. Jafar, "Effect of different media and solidifying agents on callogenesis and plant regeneration from different explants of rice (Oryza sativa L) varieties super basmati and IRRI-6," Pak. J. Bot., vol. 43, Issue. 1, pp. 487-501, 2011.

[18] A. Manickavelu, N. Nadarajan, S. K. Ganesh, R. Ramalingam, S. Raguraman, R. P. Gnanamalar, "Organogenesis induction in rice callus by cyanobacterial extracellular products," African J. Biotechnol., vol. 5, Issue. 5, pp. 437-439, 2006.

[19] A. Noor, H. Rashid, Z. Chaudhry, B. Mirza, "High frequency regeneration from scutellum derived calli of Basmati rice cv. Basmati 385 and Super Basmati," Pakistan J. Bot., vol. 37, Issue. 3, pp. 673 684, 2005.

[20] H. Khanna, S. Raina, "Genotype and culture media interaction effects on regeneration response of three indica rice cultivars," Plant Cell. Tissue Organ Cult., vol. 52, Issue. 3, pp. 145-153, 1998.

[21] D. Azria, P. L. Bhalla, "Plant regeneration from mature embryoderived callus of Australian rice (Oryza sativa L.) varieties," Aust. J. Agric. Res., vol. 51, Issue. 2, pp. 305-312, 2000.

[22] R. K. Niroula, B. P. Sah, H. P. Bimb, S. Nayak, "Effect of genotype and culture media on callus induction and plant regeneration from matured rice grain culture," J. Inst. Agric. Anim. Sci., vol. 26, pp. 2126, 2005.

[23] M. Chauhan, S. L. Kothari, "Optimization of ionic and chelated iron and its interaction with disodium ethylenediaminetetraacetic acid for enhancement of plant regeneration in rice (Oryza sativa L)," J. Plant Biochem. Biotechnol., vol. 13, Issue.1, pp. 33-34, 2004.

[24] M. Iqbal, M. Hasan, M. S. Ali, M. A. K. Mian, M. M. Hossain, M. N. Ahmed, "in vitro callus induction and plant regeneration capacity of six aromatic rice varieties," Intl. J. BioRes., vol. 15, Issue. 4, pp. 5560, 2013.

[25] Z. Y. Roly et al., "In vitro callus induction and regeneration potentiality of aromatic rice (Oryza sativa L.) cultivars in differential growth regulators," Int. J. Appl. Sci. Biotechnol., vol. 2, Issue. 2, pp. 160-167, 2014.

[26] A. Meneses, D. Flores, M. Muñoz, G. Arrieta, A. M. Espinoza, "Effect of 2,4-D, hydric stress and light on indica rice (Oryza sativa) somatic embryogenesis," Rev. Biol. Trop., vol. 53, Issue. 3-4, pp. 361-368, 2005 .

[27] P. C. Deo, R. M. Harding, M. Taylor, A. P. Tyagi, D. K. Becker, "Somatic embryogenesis, organogenesis and plant regeneration in taro (Colocasia esculenta var. esculenta)," Plant Cell. Tissue Organ Cult., vol. 99, Issue. 1, pp. 61-71, 2009.

[28] I. A. P, K. S, "Effect of hormones, explants and genotypes in in vitro culturing of sorghum," J. Biochem. Technol., vol. 1, Issue. 4, pp. $96-$ $103,2009$.

[29] X. X. Jia, J. W. Zhang, H. N. Wang, W. P. Kong, "Efficient maize (Zea mays L.) regeneration derived from mature embryos in vitro," Maydica, vol. 53, pp. 239-248, 2008.

[30] T. Abe, Y. Futsuhara, "Efficient plant regeneration by somatic embryogenesis from root callus tissues of rice (Oryza sativa L.)," J. Plant Physiol., vol. 121, Issue. 2, pp. 111-118, 1985.

[31] T. Ogawa, H. Fukuoka, H. Yano, Y. Ohkawa, "Relationships between nitrite reductase activity and genotype-dependent callus growth in rice cell cultures," Plant Cell Rep., vol. 18, Issue. 7-8, pp. 576-581, 1999.

[32] E. Maeda, T. Sato, K. Suzuki, "Microtopography and shoot-bud formation of rice (Oryza sativa) callus," Plant Biotechnol., vol. 19, Issue. 2, pp. 69-80, 2002. 
[33] K. Mitsuoka, H. Honda, H. Xing, H. Unno, "Effect of intracellular 2,4$D$ concentration on plantlet regeneration of rice (Oryza sativa L.) callus," Appl. Microbiol. Biotechnol., vol. 42, Issue. 2-3, pp. 364-365, 1994.

[34] S. B. Mostafiz, A. Wagiran, "Efficient callus induction and regeneration in selected indica rice," Agronomy, vol. 8, Issue. 5, pp. $77,2018$.

[35] H. Laukkanen, H. Häggman, S. Kontunen-Soppela, A. Hohtola, "Tissue browning of in vitro cultures of Scots pine: Role of peroxidase and polyphenol oxidase," Physiol. Plant., vol. 106, Issue. 3, pp. 337343, 1999.

[36] J. E. Preece, M. E. Compton, "Problems with explant exudation in micropropagation," in High-Tech and Micropropagation I . Biotechnology in Agriculture and Forestry, vol 17. , Bajaj Y.P.S., Ed. Springer, Berlin, Heidelberg, pp. 168-189, 1991

[37] M. Daigen, O. Kawakami, Y. Nagasawa, "Efficient anther culture method of the Japonica rice cultivar Koshihikari," Breed. Sci., vol. 50, Issue. 3, pp. 197-202, 2000.

[38] S. Prathanturarug, W. Schaffner, K. B. Biiter, "In vitro propagation of Thai medicinal plant Andrographis paniculata Nees: Impact of different cytokinnins," Beitrage Zuchtungaforsch. fur Zuchtungsforchung an Kult., vol. 2, Issue. 1, pp. 304-306, 1996.

[39] M. Inoue, E. Maeda, "Thiamine as a factor of organ formation in rice callus cultures," Japanese J. Crop Sci., vol. 49, Issue. 1, pp. 1-7, 1980.

[40] S. V. Mohamed, N. Jayabalan, "A protocol for horsegram (macrotyloma uniflrtum (Lam) verdc) callus inducation.," Isr. J. Plant Sci., vol. 44, Issue. 2-3, pp. 143-145, 1996.

[41] Z. Li, S. Duan, J. Kong, S. Li, Y. Li, Y. Zhu, "A single genetic locus in chromosome 1 controls conditional browning during the induction of calli from mature seeds of Oryza sativa ssp. indica," Plant Cell. Tissue Organ Cult., vol. 89, Issue. 2-3, pp. 237-245, 2007.

[42] Y. Yamada, Y. Zhi-qi, T. Ding-tai, "Plant regeneration from protoplast-derived callus of rice (Oryza sativa L.)," Plant Cell Rep., vol. 5, Issue. 2, pp. 85-86, 1986.

[43] A. Nishimura et al., "Isolation of a rice regeneration quantitative trait loci gene and its application to transformation systems," Proc Natl Acad Sci U S A, vol. 102, Issue. 33, pp. 11940-11944, 2005.

[44] J. H. Lee, S. Y. Lee, "Selection of stable mutants from cultured rice anthers treated with ethyl methane sulfonic acid," Plant Cell. Tissue Organ Cult., vol. 71, Issue. 2, pp. 165-171, 2002.

[45] L. YJ, Z. Qifa, "Optimising the tissue culture conditions for high efficiency transformation of indica rice," Plant Cell Rep., vol. 23, pp. 540-547, 2005.

[46] C. Gandonou et al., "Effect of genotype on callus induction and plant regeneration from leaf explants of sugarcane (Saccharum sp .)," African J. Biotechnol., vol. 4, Issue. 11, pp. 1250-1255, 2005.

[47] Z. A. Rahman, S. Roowi, S. Subramaniam, "Regeneration of Malaysian indica rice (Oryza sativa) variety Mr232 via optimised somatic embryogenesis system," J. Phytol., vol. 2, Issue. 3, pp. 30-38, 2010.

[48] S. Rueb, M. Leneman, R. A. Schilperoort, and L. A. M. Hensgens, "Efficient plant regeneration through somatic embryogenesis from callus induced on mature rice embryos (Oryza sativa L.)," Plant Cell. Tissue Organ Cult., vol. 36, Issue. 2, pp. 259-264, 1994.

[49] T. Abe, Y. Futsuhara, "Genotypic variability for callus formation and plant regeneration in rice (Oryza sativa L.)," Theor. Appl. Genet., vol. 72, Issue. 1, pp. 3-10, 1986. 